\title{
Study on Calculating Depth of Additional Stress and It's Influencing
}

\section{Factors in Multi-layered Foundation}

\author{
Xiu-he Chen ${ }^{1}$, Rui-jun Song ${ }^{2}$, Shang-xiong Chen $^{2}$, Fei YU \\ 1 Anhui Communications Planning, Design and Research Institute, Hefei 230041, China. \\ 2Institute of Rock and Soil Mechanics, Chinese Academy of Sciences, Wuhan 430071, China; \\ yufei8720@163.com
}

\begin{abstract}
Keywords: multi-layered foundation, additional stress, squeezed depth, influence laws; calculating depth

Abstracts: For widespread distribution of layered foundation, deformation and bearing capacity are two important elements in engineering project, the calculating depth of additional stress must first be established in deformation computing. For structural features of layered foundation to explore the impact factors and variation of additional stress calculating depth, an integrated impact of soil structure, soil thickness and basis width on the calculating depth has been researched. It indicates that in two-layer foundation, the soft soil has a greater impact on the depth and the calculating depth will increase with the basis width increases, but $\S_{b}$ which is the ratio of depth and basis width will reduce. Also, in multi-layered foundation, the overlying hard soil depth has little effect on the depth, depth and soft thickness with a negative correlation; with the base width increases, the calculating depth increases, $s_{b}$ presents a decreasing trend in a range. And addition, the deformation ratio method is proposed to determine the calculating depth of additional stress in multi-layered foundation which is with a obvious structure of layer.
\end{abstract}

\section{Introduction}

The surface of the Northern Anhui is widely covered by the flood deposits in southern Yellou River and Huaihe with a complicated geological conditions and significant characteristic of alternating layer [1], and the bearing capacity and deformation was an important problem in engineering construction. At present, according to the bearing capacity of multi-layered foundation, many scholars put forward a lot of modified formula about foundation bearing capacity based on the basis of the calculation formula of the homogeneous foundation bearing capacity[2-4], which mainly are the diffusion angle method, punching shear method and strength weighted average method[5]. The depth of compressed layer of multi-layered foundation was established by the calculating depth of additional stress under the load which had an important role in the calculation of the multi-layered foundation settlement related to engineering geological prospecting, ground treatment and settlement control etc..

For the additional stress calculation of the multi-layered foundation settlement, He Guhua [6]proposed a calculation method can be used to solve the complex geologic stratification with the width of the foundation for 10 to 30 meters and buried depth of 5 meters and made a list of the adjustment coefficient table of calculated depth according to the experimental results; Xia Zhengzhong[7] using viscous elasto-plastic model, combined with ground connection strength theory, gives the formula about the calculated depth of effective subsidiary stress and the method is that the soil will not have significant deformation when the additional stress generated by the external load is equal to the connection strength of the soil; Wang Fengchi[8] studied the effect of foundation length width ratio on the subsoil compressive depth. The conclusion is that when the 
length and width of the base are similar using the method of He Guhua to calculate the thickness of the compressed layer, or should use the empirical formula; Wen Zhongxu[8] comprehensively studied the applicability of several methods on the calculation formula of the depth for the equal foundation settlement in the conditions of different foundation size, additional pressure at foundation bottom, foundation embedded depth, and the different depth of ground water level and double-layered foundation, which obtains that stress method is more closer to the actual settlement monitoring results than the deformation ratio method. The above calculation method and research conclusion had some positive effect on the determination of calculation depth for the additional stress of multi-layered foundation, each had its own applicability, but there was no systematic study the influence factors and laws of the calculation depth.

With the development of computer software, hardware and the theory of finite element, the numerical analysis method was more and more used in the field of rock and soil. Although the numerical calculation method was complex, the constitutive model and parameter calculation error were large, but it could be satisfied with the advantages of non-linear, heterogeneous and relatively low cost, and could simulate various conditions for the given conditions and parameters, the results were accurate. Therefore, numerical methods could be used to study the influence factors and laws of the calculation depth of the additional stress for multi-layered foundation.

According to the structural characteristics of multi-layered foundation, using FLAC3D numerical analysis method to comparative study the different wear conditions, explore the influence factors and laws of the calculation depth of the additional stress for multi-layered foundation, and generalized analysis the influence factors on soil structure, thickness and foundation width to calculation depth, which provided reference for the scene investigation, foundation treatment and foundation settlement control of multi-layered foundation.

\section{The formulas for determining the calculation depth}

The calculation depth of additional stress for layered foundation under load, that is, the depth of compression layer is related to the soil structure of foundation, the thickness of soil layer and foundation width, and so on. In engineering, there were two methods to determine the depth of calculation for settlement deformation, namely, the stress ratio method and the deformation ratio method. In addition, the specification $[10,11]$ also recommended an empirical formula.

The stress ratio method. The stress ratio method was based on the value of additional stress and self-weight stress at a depth below the center of the base to confirm the influence depth.

$$
\alpha \leq \sigma_{z} / \sigma_{h}
$$

In the formula, the $\sigma_{z}$ was the additional stress of foundation bottom center at the depth of $\mathrm{z}, \sigma_{h}$

was the self-weight stress of the same depth at $\mathrm{z}, \quad \alpha$ was the stress ratio, for the general soil was 0.2 , the soft soil was 0.1 .

The meaning of this method was that the additional stress was decreased with the diffusion of the depth when reaching the depth of $\mathrm{z}$ at the bottom of the foundation, the additional stress was so small that it could be neglected for causing the settlement of the soil layer, which could be considered as the calculation depth of additional stress.

The deformation ratio method. The deformation ratio method based on the ratio of the last layer of soil deformation and total deformation to confirm the influence depth. 


$$
\Delta s_{n} \leq 0.025 \sum_{i=1}^{n} \Delta s_{i}
$$

In the formula, $\Delta \mathrm{s}_{\mathrm{i}}$ was the settlement of $\mathrm{i}$ layer of the thin soil at the range of calculation depth, $\Delta \mathrm{s}_{\mathrm{n}}$ was the calculated deformation value of soil layer with the thickness of $\Delta \mathrm{z}$ above the layer of influence depth.

The meaning of this method[12] was that taking the layer with the thickness of $\Delta z$ at a depth of $\mathrm{z}$ below the basement, the amount of compression was only 0.025 times of the total compression under the effect of additional stress, and the depth of $\mathrm{Z}$ could be considered as the calculation depth of additional stress.

The empirical formula. The recommended that when there was no effect of the adjacent load and the foundation width was at the range of 1 to $30 \mathrm{~m}$, the calculation depth of the foundation deformation on the midpoint of foundation could be calculated by the simplified formula.

$$
z=b(2.5-0.4 \ln b)
$$

In the formula, $\mathrm{b}$ was foundation width, and the application range was 1 to $30 \mathrm{~m}, \mathrm{z}$ was the calculation depth.

The empirical formula was summed by a large number of engineering practice, which had a strong commonality, the specification recommended to use it when lacking of the necessary survey data or validating the definite depth of the stress ratio method and the deformation ratio method Three formulas provided the standard from different angles for confirming the calculation depth, overall, the calculation depth were related to soil structure of foundation, thickness of soil layer and the width of the foundation, and the influence rules of various factors were different.

To use the FLAC3D numerical analysis method, combined with the structure characteristics of multi-layered foundation in Northern Anhui with the methods of stress ratio, deformation ratio and empirical formula to comparative study the calculation depth of additional stress on multi-layered foundation under different conditions and analysis the influence of each factor.

\section{Calculating schemes}

Calculation model. The subgrade bearing capacity as the object of research to study the calculation depth of additional stress on multi-layered foundation

The foundation bearing capacity was a plane strain problem, and the load and foundation were symmetrical to the vertical face, so the design adopted the way of establishing the half model. The embedded depth of foundation was $2.5 \mathrm{~m}$, the gravity was applied to the surface of foundation on the overlying soil layer, and the upper load was directly applied to the foundation bed. In order to avoid the influence of the boundary effect, the total width of the model is $12.5 \mathrm{~m}$, which was the 5 15 times of the foundation width. The foundation depth was $20 \mathrm{~m}$, which was the 7 20 times of the foundation width, as shown in figure 1. 


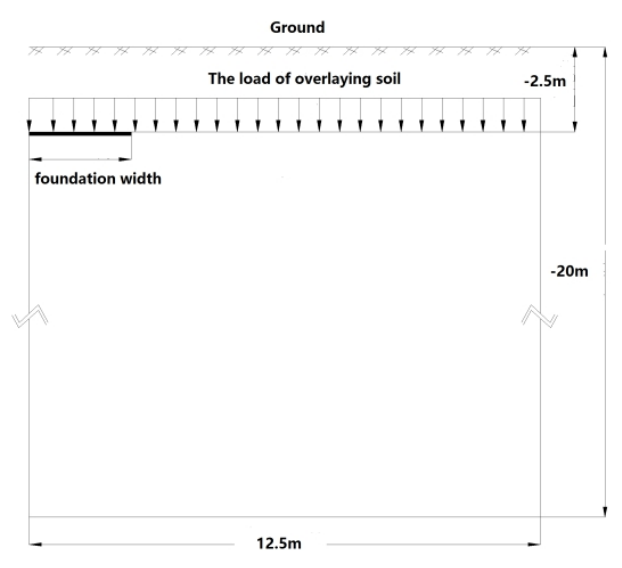

Fig.1 Schematic diagram of model

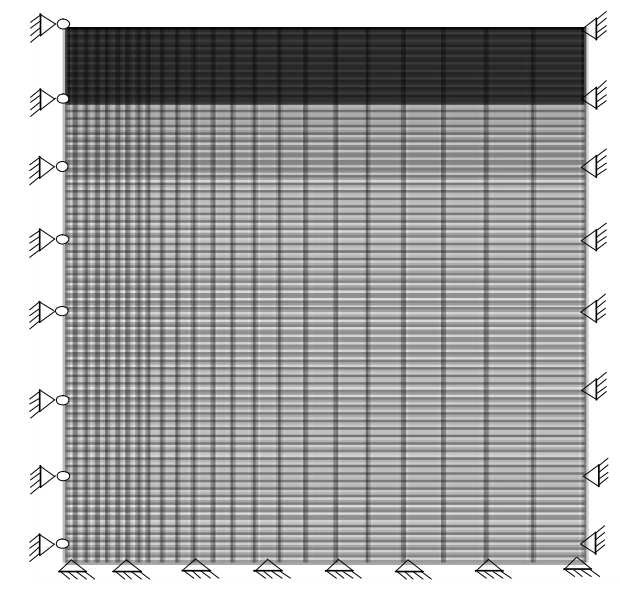

Fig.2 Grid diagram of computing model

To set up the calculation model and divide the grid according to the geometric model. The left boundary of the model is the symmetry plane, and the top surface was the foundation bed. The upper layer of the model is applied to the gravity of the overlaying soil, the left fixed horizontal displacement of the $\mathrm{x}$, and the right and the bottom were fixed, and the whole model fixed the displacement of y direction, as shown in figure 2 .

Calculation parameters. The numerical calculation designed two types of soil which was hard soil and soft soil, and adopted Mohr Coulomb model and yield criterion of traditional limit equilibrium methods. Calculation parameters was mainly based on test results of typical geological soil in Northern Anhui, and referred project geology handbook to determine synthetically, as shown in table 1.

Table 1 Table of calculation parameters

\begin{tabular}{ccccc}
\hline parameter & $\begin{array}{c}\text { deformation } \\
\text { modulus/MPa }\end{array}$ & poisson's ration & cohesive force/kPa & $\begin{array}{c}\text { internal friction } \\
\text { angle/ }\end{array}$ \\
\hline soft soil & 6 & 0.4 & 6 & 10 \\
hard soil & 18 & 0.25 & 30 & 24 \\
\hline
\end{tabular}

Calculated conditions. The double-layered ground was designed two types of foundation which were upper-soft-and-lower-hard and upper-hard-and-lower-soft, and the soil property of the third layer of soil is the same as the second layer. The multi-layered soil was designed with weak intercalated foundation, the second layer of soil was soft soil in model, and the first and third layer was hard soil. The basic buried depth of all conditions was $2.5 \mathrm{~m}$.

The foundation of upper-soft-and-lower-hard: the foundation width was $4.0 \mathrm{~m}$, and the thickness of the first layer of soil were $1.0 \mathrm{~m}, 2.0 \mathrm{~m}, 3.0 \mathrm{~m}, 4.0 \mathrm{~m}$, a total of 4 cases.

The foundation of upper-hard-and-lower-soft: the foundation width was $4.0 \mathrm{~m}$, and the thickness of the first layer of soil were $1.0 \mathrm{~m}, 2.0 \mathrm{~m}, 3.0 \mathrm{~m}$, the first layer was $2.0 \mathrm{~m}$, the foundation width were $1.5 \mathrm{~m}, 2.5 \mathrm{~m}, 3.5 \mathrm{~m}, 5.0 \mathrm{~m}$, a total of 8 cases.

The multi-layered foundation: the hard layer of the first soil was $2.0 \mathrm{~m}$, and the thickness of weak intercalated layers were $1.0 \mathrm{~m}, 2.0 \mathrm{~m}, 3.0 \mathrm{~m}$; the foundation width was $4.0 \mathrm{~m}$, and the soft layer of the second soil was $1.0 \mathrm{~m}$, the hard layer of the first soil were $1.0 \mathrm{~m}, 1.5 \mathrm{~m}, 2.0 \mathrm{~m}$; the hard layer of the first soil was $2.0 \mathrm{~m}$, and the thickness of weak intercalated layers was $1.0 \mathrm{~m}$, the foundation width were $1.5 \mathrm{~m}, 2.0 \mathrm{~m}, 2.5 \mathrm{~m}$ and $3.0 \mathrm{~m}, 3.5 \mathrm{~m}, 5.0 \mathrm{~m}$, a total of 12 cases.

\section{Model examination}

To studying on the ultimate bearing capacity of the homogeneous hard soil with foundation embedded depth of $2.5 \mathrm{~m}$ and the foundation width of $4.0 \mathrm{~m}$. 
Table 2 Calculating depth of soft layer foundation

\begin{tabular}{cccc}
\hline \multirow{2}{*}{ foundation width $/ \mathrm{m}$} & \multicolumn{3}{c}{ calculation method } \\
\cline { 2 - 4 } & stress ratio method $/ \mathrm{m}$ & deformation ratio method $/ \mathrm{m}$ & empirical formula $/ \mathrm{m}$ \\
\hline 1.5 & 2.1 & 3.2 & 3.5 \\
2.5 & 3.7 & 5.2 & 5.3 \\
4.0 & 5.9 & 5.6 & 7.8 \\
5.0 & 8.7 & 6.1 & 9.3 \\
\hline
\end{tabular}

To calculate the ultimate bearing capacity of homogeneous hard soil foundation with capacity formulae by Terzaghi [12]: When the internal friction angle was 24 degrees in the correlation chart of the ultimate bearing capacity, it was 9, 10, 23 respectively, and the ultimate bearing capacity was $1428 \mathrm{kPa}$ with the natural unit weight of hard soil, the value calculated with the model was $1370 \mathrm{kPa}$ differed from $4.06 \%$ of the formula calculation, which shows the correctness of the model.

In addition, to calculate the depth value of the additional stress on the homogeneous soft soil foundation and hard soil foundation in different foundation width respectively, the results were shown in table 2 and table 3 :

Table 3 Calculating depth of rigid layer foundation

\begin{tabular}{cccc}
\hline \multirow{2}{*}{ foundation width $/ \mathrm{m}$} & \multicolumn{3}{c}{ calculation method } \\
\cline { 2 - 4 } & stress ratio method $/ \mathrm{m}$ & deformation ratio method $/ \mathrm{m}$ & empirical formula $/ \mathrm{m}$ \\
\hline 1.5 & 7.1 & 4.2 & 3.5 \\
2.5 & 8.6 & 10.8 & 5.3 \\
4.0 & 9.9 & 12.4 & 7.8 \\
5.0 & 10.5 & 15.3 & 9.3 \\
\hline
\end{tabular}

\section{The calculation results and influencing factors}

In order to determine the maximum depth of additional stress in the foundation, the characteristic value of the bearing capacity was selected as the calculation of the external load. At the same time, in order to make the analysis more practical significance to the engineering, the $s_{b}$ was defined as the ratio of the depth and the width of the calculation, and $s_{b s}$ and $s_{b d}$ were used to represent the $\mathrm{S}_{b}$ value of the stress ratio method and the deformation ratio method respectively.

The influence of foundation condition. Only the foundation with weak interlayer was considered for multi-layer foundation. Figure 6 and figure 5 were the results in the calculation depth of the additional stress with weak interlayer, and the foundation width was $4.0 \mathrm{~m}$, the calculation depth changed in different soft soil and the thickness of upper hard soil layer.

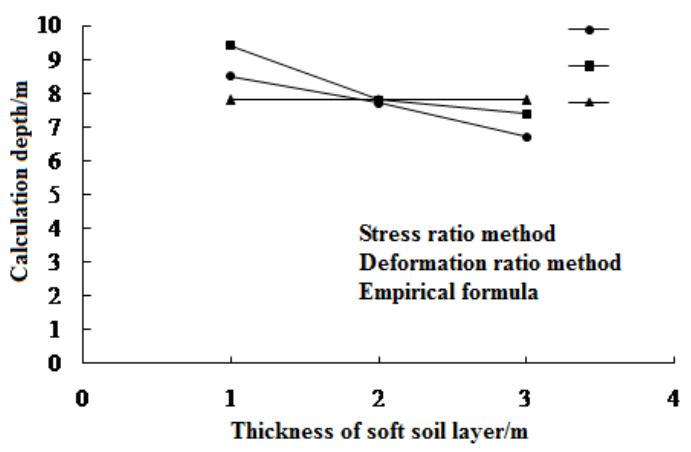

Fig.5 Calculating depth of multi-layered foundation in different soft layer thickness

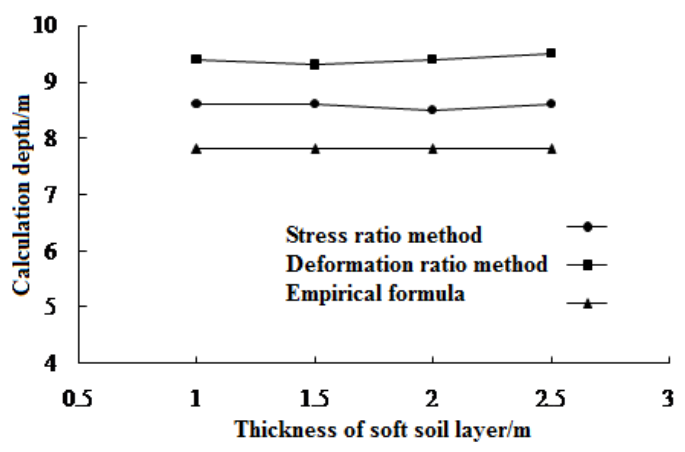

Fig.6 Calculating depth of multi-layered foundation in different upper rigid layer thickness

As was shown in Figure 5, the calculation depth was gradually decreased with the increase of the thickness of soft soil interlining in multi-layer foundation with weak interlayer. Because of the low 
strength of soft soil, the stress applied from base to the foundation transfer to the soft soil. The soft soil appeared to be destroyed and developed to the lateral, and the stress dissipation was faster, the lateral deformation of soft soil layer was increased. Because the deep part cannot transfer the stress, and the deformation was very small, so the influence depth was lesser. The empirical formula was not reasonable to consider the influence of the properties of layer on the calculation depth, which was obviously not reasonable.

As was shown in Figure 5, the calculation depth of the additional stress in deformation ratio method was larger than stress ratio method. Comparing with the homogeneous hard soil foundation, when the foundation width was $4.0 \mathrm{~m}$, the first hard soil layer was $2.0 \mathrm{~m}$, and the soft soil layer was $1.0 \mathrm{~m}$, the calculation depth value of additional stress reduced by $14 \%$ with stress ratio method, and the deformation ratio method reduced by 24\%; When the thickness of the soft soil interlining increased to $3 \mathrm{~m}$. The calculated depth value was reduced obviously, and the stress ratio method reduced by $32 \%$, deformation ratio method decreased by $40 \%$. So, the soft soil interlining of foundation had a great influence in the calculation depth of the additional stress.

As was shown in Figure 6, the calculation depth value of the additional stress remained unchanged when the thickness of the overlying soil layer is changed. This was mainly due to the larger stress field in the superficial part. The thickness of soft soil layer was thin or same (all were $1 \mathrm{~m})$ for the foundation with weak interlayer, although the partial stress was dissipated faster in the soft soil layer, it still could be passed down, so the thickness of the soft soil layer was the main factor that affected the propagation depth of stress. In addition, the deformation ratio method was larger than the stress ratio method, and the stress ratio method was larger than the empirical formula among different methods.

For multi-layer foundation with weak interlayer, the thickness of hard crust layer was in $1 \sim 2.5 \mathrm{~m}$, the calculation depth of additional stress changed little; When the thickness of soft soil layer was increased from $1.0 \mathrm{~m}$ to $3.0 \mathrm{~m}$, the calculated depth of additional stress was decreased obviously, and the soft soil layer had great influence on the calculation depth of additional stress to multi-layer foundation.

Effect of foundation width. (1)The multi-layer foundation with upper- soft-and-lower-hard. The thickness of hard soil layer was $2.0 \mathrm{~m}$ in the multi-layer foundation with upper- soft-and-lower-hard, the results of calculation depth of additional stress in different foundation width, and the change plot of $s_{b}$ with the foundation width, as was shown in figure 7 .

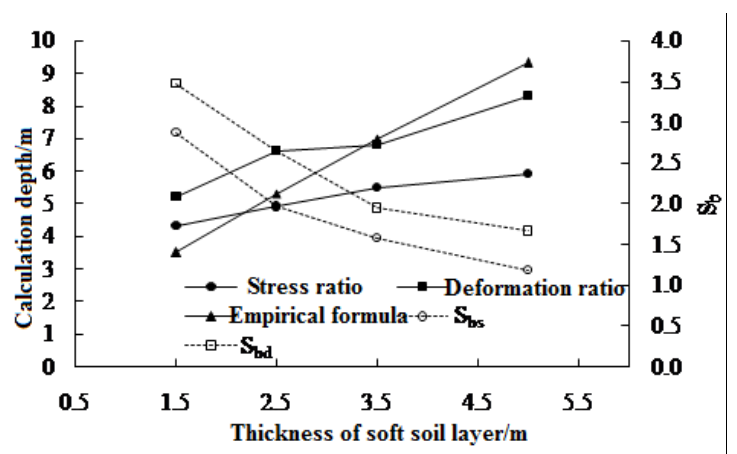

Fig.7 Calculating depth of rigid upper layer and soft lower layer foundation in different basis width

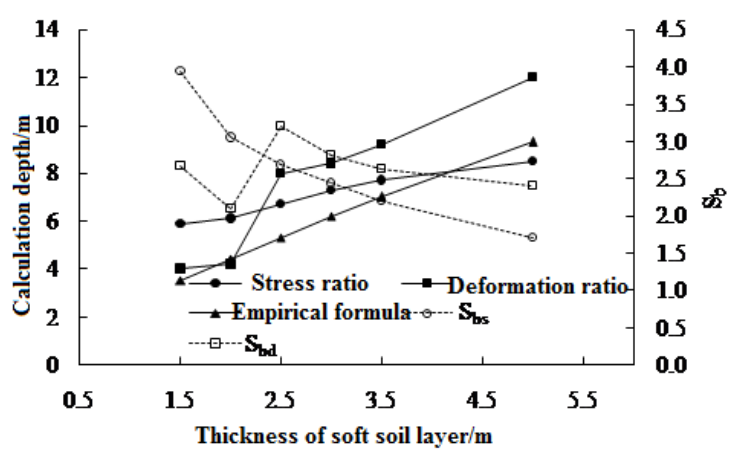

Fig.8 Calculating depth of multi-layered

foundation in different basis width

As was shown in Figure 7, the calculation depth value of the additional stress was increased with the increase of the foundation width. When the foundation width increased from $1.5 \mathrm{~m}$ to $5 \mathrm{~m}$, the calculations of stress ratio method and deformation ratio method increased respectively $37.2 \%$ and 
$59.6 \%$. At the same time, the result of stress ratio method is less than the deformation ratio method, mainly because of the large deformation of soft soil. The results of empirical formula were smaller than other two methods when the foundation width was small, and the opposite cases for larger foundation width.

As was shown in Figure 7, the value of $\mathbf{S}_{b}$ was decreased with the increase of the foundation width in the multi-layer foundation with upper- soft-and-lower-hard. When the foundation width increased from 0.75 times to 2.5 times that was the thickness of hard shell layer (the thickness of hard shell layer was $2.0 \mathrm{~m}$ ), $\mathrm{s}_{b s}$ reduced from 2.87 to 1.18 , and $\mathrm{s}_{b d}$ reduced from 3.47 to 166 , the damping decreased $58.89 \%$ and $52.16 \%$ respectively.

(2)Multi-layer foundation with weak interlayer. The thickness of the first hard soil layer was $2.0 \mathrm{~m}$ in the multi-layer foundation with weak interlayer, and the weak interlayer was $1.0 \mathrm{~m}$, the results of calculation depth of additional stress in different foundation width, and the change plot of $\mathrm{s}_{b}$ with the foundation width, as was shown in figure 8.

As was shown in Figure 8, the calculation depth of additional stress was gradually increased with the increase of the thickness of foundation width in multi-layer foundation with weak interlayer. This was because that the range of stress diffusion was increased with the increase of foundation width, so the range of the influence in stress was deeper, and the additional stress calculation depth was increased. When the foundation width increased from $1.5 \mathrm{~m}$ to $5 \mathrm{~m}$, the calculations of stress ratio method and deformation ratio method increased respectively $44 \%$ and $200 \%$. At the same time, the increasing trend of stress ratio method was slowly, and the deformation ratio method was the biggest.

As was shown in Figure 8, the value of $s_{b s}$ was decreased with the increase of the foundation width in the multi-layer foundation with upper- soft-and-lower-hard. When the foundation width increased from 0.5 times to 2.5 times that was the thickness of hard shell layer (the thickness of hard shell layer was $2.0 \mathrm{~m}), \mathrm{s}_{b s}$ reduced from 3.93 to 1.70 , and the regularity of $\mathrm{s}_{b d}$ with the increase of the foundation width was that the first reduced, and then increased, finally to decrease. When the thickness of the foundation width was equal to the first hard soil layer, the $\boldsymbol{s}_{b d}$ had a minimum value.

It was easy to find that the change rule of the calculation depth of additional stress was the same as homogeneous hard soil foundation with the increase of the thickness of foundation width in multi-layer foundation with weak interlayer (the calculation depth was both increased), just the value of calculation depth would be reduced; At the same time, the change rule of $\mathbf{S}_{b}\left(\boldsymbol{S}_{b s}\right.$ and $\left.s_{b u}\right)$ was the same as homogeneous hard soil foundation with the different thickness of foundation width: it would be decreased with the increase of foundation width.

\section{Conclusion}

According to the structural characteristics of multi-layered foundation, using FLAC3D numerical analysis method to explore the influence factors and change rules of the calculation depth of 
additional stress for multi-layered foundation in different working conditions, and generalized analysis the influence factors on soil structure, thickness and foundation width to the calculation depth of additional stress, which obtained some conclusions to provide reference for the scene investigation, foundation treatment and foundation settlement control of multi-layered foundation.

(1) The value of $\mathbb{S}_{b}$ decreased gradually with the increase of the thickness of soft soil layer in the multi-layer foundation of upper- soft-and-lower-hard, which was significantly reduced than homogeneous foundation; The value of $\mathbf{S}_{b}$ increased gradually with the increase of the thickness of soft soil layer in the multi-layer foundation of upper- hard-and-lower-soft, which was larger than homogeneous foundation.

(2) The calculation depth of additional stress was significantly decreased with the increase of the thickness of foundation width in multi-layer foundation with weak interlayer, and the maximum reduction was about $40 \%$ in this paper; the calculation depth of the additional stress remained unchanged with the change of the thickness in overlying hard soil.

(3) The calculation depth of additional stress was increased with the increase of the thickness of foundation width in multi-layered foundation, and the maximum reduction was about $200 \%$ in this paper, but the value of $s_{b}$ had a decreasing trend.

(4) The soft soil effected calculation depth of the multi-layer foundation, when the thickness of the soft soil layer and foundation width were changed, the value of the calculation depth varied greatly.

(5) According to the results of this paper, the deformation ratio method reflected the inhomogeneity on the foundation. So, using the deformation ratio method to confirm the foundation depth of the additional stress in a significant multi-layer foundation.

\section{Reference}

[1] Jin Quan. The Quaternary in the Huaibei Plain of the Anhui Province [M]. Beijing: Geological Publishing House, 1990.

[2] HANNA A M, MEYERHOF G G. Ultimate Bearing Capacity of Foundations on a Three-layer Soil, with Special Reference to Layered sand [J]. Canadian Geotechnical Journal, 1979, 16(02): 412-414.

[3] KRAFT L M, HELFRICH S C. Bearing Capacity of Shallow Footing, Sand over Clay [J]. Canadian Geotechnical Journal, 1983, 20(01): 182-185.

[4] Qin Huilai, Huang Maosong. Upper-bound Method for Calculating Bearing Capacity of Strip Footings on Two-layer Soils [J]. Chinese Journal of Geotechnical Engineering, 2008, 30(04): 611-616.

[5] Yuan Fanfan, Luan Maotian. Methods for Estimating Bearing Capacity of Layered Foundations in Harbor Engineering [J]. Rock and Soil Mechanics, 2006, 27(04): 1124-1128.

[6] He Yihua, Ji Wanru. Method for Calculating Compression Depth of Subsoil under Large Foundation [J]. Journal of Building Structures, 1984, (01): 56-63.

[7] Xia Zhengzhong. Method of Calculating the Deformation of Subsoil and the Effective Depth of Compressible Stratum [J]. Chinese Journal of Geotechnical Engineering, 1984, 6(01):18-31.

[8] Wang Fengchi, Zhu Fusheng. Effect of Foundation Length-width Ratio on Compressed Layer Depth [J]. Journal of Shenyang Jianzhu University (Natural Science), 2006, 22(01): 57-60. 
[9] Xu Wenzhong, Xu Jishu. Analysis the Calculation Depth of Settlement on Soft Soil Foundation [J]. Geotechnical Engineering World, 2008, 11(05): 20-26.

[10]JTG D63-2007 Specifications for Design of Groundsill and Foundation of Highway Bridges and Culverts $[\mathrm{S}]$.

[11] Cen Xizhe. Ground Foundation and Soil Mechanics[M]. Beijing: Tsinghua University Press, 2004. 